\title{
Stock Market Model in Romanian Pharmaceutical Sector
}

\author{
Adina Ionela Străchinaru, Lavinia Mihaela Guțu, and Vasile Ilie
}

\begin{abstract}
When making an investment decision it is very important to analyze the profitability and the portfolio risk. The evolution of the stock prices included in the portfolio can influence the overall portfolio profitability. A major risk of a single share can bring a surplus of risk to the overall portfolio. It is also important to analyze the market as one stock can influence the entire market. With this in view, this paper aims at analyzing the impact that the risk of a single stock has on the portfolio or the modification determined by the price of a stock on the entire portfolio return.
\end{abstract}

Index Terms-Investment decision, portfolio rentability, portfolio risk, stock market model.

\section{INTRODUCTION}

The investment decision requires a rigorous analysis of the financial instruments. Based on this analysis it seeks to determine the correct price of financial assets and to evaluate them. Starting from the theory developed by Markowitz, W., Sharpe (1964) [1] found a link between a financial asset's profitability and the market portfolio's return. His model, Capital Asset Pricing Model, represents a crucial step in the evaluation of the primary financial instruments. Therefore, this paper will analyze unifactorial models of the primary financial instruments assessment (CAPM).

The CAPM was developed independently by W., Sharpe (1963, 1964), J., Treynor (1961) [2], J., Mossin (1966) [3], and J., Lintner $(1965,1969)$ [4]. This model succeeded in highlighting a relationship between a financial asset's profitability and the return of a fully diversified portfolio. Later, the literature has widely studied this phenomenon. Later, the CAPM model was widely used to analyze the asset pricing such as J., H., Cochrane (2001) [5] or the market inefficiency like L. A. Stout (2002-2003) [6] or the risk premia as M. Lettau and S. Ludvigson (2001) [7]. The most recently works have studied the market risks like A., Carol (2008) [8], the adequate portfolio and investment decision management like A. V., Rutkauskas, V. Stasytyte, and J., Borisova (2009) [9], the investment decision modeling as A. V., Rutkauskas, A., Miečinskienè (2008), and V., Stasytytė [10] did, portofolio with free-risk asset like F. Serban, M. V. Stefanescu and S. Dedu (2011) [11] or investments during financial the crisis as M. C., Stefan (2012) [12] did.

\section{The Methodology And Data Used}

This work analyzes unifactorial models used for the

Manuscript received August 25, 2013; revised October 20, 2013.

The authors are with Bucharest University of Economic Studies, Romania (e-mail: adina.strachinaru@yahoo.com, laviniamihaela.gutu@gmail.com, vasile.ilie@fin.ase.ro). evaluation of the primary financial instruments (CAPM) for the most representative companies on the Romanian pharmaceutical market. In this respect closing prices for the following: ATB, BIO, RMAH, SCD, FAMD, FITO, MEDU, and SINT (Category I: ANTIBIOTICE S.A., BIOFARM S.A.; Category II: FARMACEUTICA REMEDIA S.A. and ZENTIVA S.A.; Category III: MEDIMFARM S.A. PLOIEŞTI, FITOTERAPIA S.A. BUCUREŞTI, MEDUMAN S.A. Vişeu de Sus and SINTOFARM S.A. BUCUREŞTI) and the composite index on the Romanian capital market, BET-C have been used. Values were taken from the Bucharest Stock Exchange website, but also from the specialized websites such as: onlinebroker.ro, intercapital.ro, etc.

In order to achieve the case study, monthly indicators (from January 2006 to August 2013) for the stock returns have been used. The scope is to capture short-term portfolio variations on the Romanian pharmaceutical market from the early stages of the current global financial crisis to present. Stock yields were obtained based on closing prices.

\section{ESTIMATION OF INDICATORS AND INTERPRETATION OF RESULTS}

In the econometric analysis, in order to obtain valid results, the outline is removed and its value is replaced with the average yield of each share. Thus, the series have been adjusted. In all graphs, the CAPM model is used after eliminating the outline.

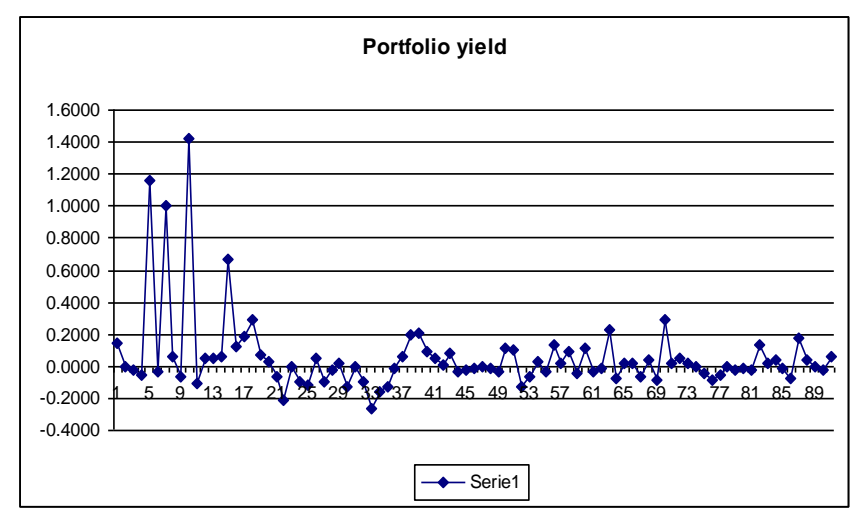

Fig. 1. Portfolio yield.

As is shown in Fig. 1, theoretically, it is made the assumption that the market portfolio includes all risky assets existing on capital markets. In fact, in practice it is difficult to estimate the price of a hybrid portfolio that includes stocks, bonds, mortgages, etc.. For this reason, an index that reflects the overall market tendency or the market performance is used as a proxy for the market portfolio. For example, for the Romanian capital market BET-C index has been used as a proxy. BET-C includes the price evolution of all companies 
listed on the Bucharest Stock Exchange regulated market, Category I and II, except for SIFs.

Being the risk distinction in the market risk (systematic) and specific risk (unsystematic), the factorial models try to explain these two risk components.

So, the market model (having one parameter), which estimates the CAPM model equation, has the following form:

$$
E\left(R_{i}\right)-r f=\alpha_{i}+\beta_{i}\left(E\left(R_{M}\right)-r f\right)+\varepsilon_{i}
$$

or

$$
E\left(R_{i}\right)=\alpha_{i}+\beta_{i} E\left(R_{M}\right)+\varepsilon_{i}
$$

where $E\left(R_{i}\right)=$ risky financial asset return; $(r f)=$ risk-free asset return, $E\left(R_{M}\right)=$ market portfolio return, $(E(R M)-r f)=$ market risk premium adjusted with a beta indicator specific for each action, $\alpha=$ constant (intercept), $\beta=$ market risk component and indicates the sensitivity of the asset $i$ return to the return of the market portfolio, $\varepsilon=$ specific risk component, diversified, encompassing random events that affect a share, and is actually the regression residue.

The CAPM ("Capital Assets Pricing Model") model result described in the above relations is very important. Formulas indicate the relationship between a risky financial asset return and the return of a fully diversified portfolio through the risk indicator beta $(\beta)$.

In other words, the indicator beta for a specific share is the risk excess brought to a well-diversified portfolio caused by one percentage point weight increasing for this share.

\section{Testing the SignificAnce OF THE Regression MODEL PARAMETERS}

\section{A. The Student Test}

As a result of the parameters estimation, each share reacts differently from the market portfolio and has specific characteristics.

Therefore, in the case of the ATB share, statistically we can state the following, as shown in the figure below: $\alpha$ (intercept $=c$ ) registers a $P$-value of $0,4355>0,05$ (where $5 \%$ is the fixed significance threshold, for $\alpha=95 \%$ (prob $=1$ $\alpha=0,95$ ), which means that $\alpha$ is not significantly different from 0 (the regression model is not correctly specified); and $\beta$ (BETC_YIELD) records a probability of $0,0000<0,05$ (see Fig. 2), I mean with a probability of $95 \% \beta$ is significantly

\begin{tabular}{|c|c|c|c|c|c|c|c|c|}
\hline Symbol & $\mathrm{P}$-value & Coefficient $\alpha$ & Coefficient $\beta$ & R-squared & $\begin{array}{c}\text { Adjusted } \\
\text { R-squared }\end{array}$ & $\begin{array}{c}\text { S.E. of } \\
\text { regression }\end{array}$ & $\begin{array}{c}\text { Jarque-Bera } \\
\text { test } \\
\text { probability }\end{array}$ & $\begin{array}{c}\text { Wald test probability } \\
\text { F-statistic }\end{array}$ \\
\hline ATB & 0.0000 & -0.0064 & 0.5155 & 0.2622 & 0.2539 & 0.0783 & 0.0000 & 0.0000 \\
\hline $\mathrm{BIO}$ & 0.0000 & 0.0037 & 0.9257 & 0.3380 & 0.3306 & 0.1172 & 0.0000 & 0.0000 \\
\hline RMAH & 0.0045 & 0.0498 & 0.9749 & 0.0872 & 0.0769 & 0.2855 & 0.0000 & 0.0212 \\
\hline SCD & 0.0000 & 0.0012 & 0.5037 & 0.2236 & 0.2149 & 0.0849 & 0.0027 & 0.0000 \\
\hline FAMD & 0.7931 & 0.0744 & 0.2825 & 0.0008 & -0.0105 & 0.9167 & 0.0000 & 0.0103 \\
\hline FITO & 0.7428 & 0.0432 & 0.1373 & 0.0012 & -0.0100 & 0.3561 & 0.0000 & 0.0000 \\
\hline MEDU & 0.0013 & 0.0087 & 0.5606 & 0.1098 & 0.0998 & 0.1445 & 0.0000 & 0.8438 \\
\hline SINT & 0.4106 & 0.0385 & 0.2927 & 0.0076 & -0.0035 & 0.3022 & 0.0000 & 0.0000 \\
\hline
\end{tabular}
different from zero.

Source: own calculations

Dependent Variable: ATB_YIELD

Method: Least Squares

Date: 09/19/13 Time: 23:36

Sample: 191

Included observations: 91

\begin{tabular}{lrlll}
\hline \hline \multicolumn{1}{c}{ Variable } & Coefficient & Std. Error & t-Statistic & Prob. \\
\hline \hline C C & -0.006427 & 0.008204 & -0.783346 & 0.4355 \\
BETC_YIELD & 0.515544 & 0.091671 & 5.623863 & 0.0000 \\
\hline \hline R-squared & 0.262194 & Mean dependent var & -0.006101 \\
Adjusted R-squared & 0.253904 & S.D. dependent var & 0.090606 \\
S.E. of regression & 0.078263 & Akaike info criterion & -2.235758 \\
Sum squared resid & 0.545130 & Schwarz criterion & -2.180574 \\
Log likelihood & 103.7270 & F-statistic & 31.62783 \\
Durbin-Watson stat & 1.612966 & Prob(F-statistic) & 0.000000
\end{tabular}

Fig. 2. The regression model for the ATB.

The same thing happens in the case of BIO, RMAH, SCD and MEDU, whose estimated coefficients are significant statistically. On the other hand, we cannot say the same thing about FAMD, FITO and SINT shares, because the probability value associated with each coefficient is greater than the significance threshold of $5 \%$, as you can see in Table I.

\section{B. Risk and Yield Coefficients}

Alpha coefficient $(\alpha)$ represents the difference between the current average return and the forecast average return. In general, we can say that an $\alpha$ equal to zero highlights an asset to be properly evaluated. Usually, the values of $\alpha$ are less than one. A positive $\alpha$ indicates that the financial asset is undervalued, while a negative $\alpha$ indicates that financial asset is overvalued. According to the estimates, the values presented in Table I, we can talk about a overvaluation only in the case of the ATB, the rest of the shares are undervalued.

Beta coefficient $(\beta)$ (BET-C index) is the systematic risk indicator and measures the sensitivity of the shares on the market, I mean the expected average return. If it is greater than 1 , it reacts more aggressive than the market portfolio, and if it is less than 1 , it reacts weaker than the market portfolio.

According to Table I, the $\beta$ coefficient value $<1$, so the entire portfolio of shares, made up of the most important and significant companies of the pharmaceutical sector, reacts weaker than market portfolio (has a low risk).

The specific risk of each share is also represented by 
means of S.E. of the regression indicator and, according Table I, we can state that the ATB share is risky at a rate of $7,83 \%$; the BIO share has a risk of $11,72 \% ; 28,55 \%$ RMAH; 8,49\% SCD; 91,67\% FAMD; 35,61\% FITO; 14,45\% MEDU and, respectively, 30,22\% SINT. Therefore, within the most representative companies in the Romania`s pharmaceutical industry, for the period from January 2006 to August 2013, the share with the greatest risk in trade on the Bucharest Stock Exchange is represented by the company MedimFarm S.A. Ploiesti (FAMD), and the less risky action for the reporting period is represented by the symbol of the ATB, respectively Antibiotics S.A., a slight difference of $0.68 \%$ of Zentiva S.A.

\section{Testing the Stability of the Estimated $\beta$ Coefficient by the Market Model - Wald Test}

The coefficient $\beta$ (BET-C index) estimated by the market model is quite significant for the market, the Romanian pharmaceutical market respectively, but its stability must be tested, as a necessary and mandatory condition. Therefore, in order to achieve a properly specified model and obtaining valid results, we tested the stability of the $\beta$ coefficient using the Wald test, as Fig. 3 shows (see also Table I).

\begin{tabular}{|c|c|c|c|}
\hline Test Statistic & Value & $d f$ & Probability \\
\hline F-statistic & 0.039060 & $(1,89)$ & 0.8438 \\
\hline Chi-square & 0.039060 & 1 & 0.8433 \\
\hline
\end{tabular}

Null Hypothesis Summary:

\begin{tabular}{lll}
\hline \hline Normalized Restriction (=0) & Value & Std. Err. \\
\hline \hline -C(1) - BETC_YIELD*C(2) + ... & 0.003031 & 0.015338 \\
\hline \hline
\end{tabular}

Restrictions are linear in coefficients

Fig. 3. Wald test for MEDU share.

It can be seen that the probability associated with the Wald test, represented by F-statistic, exceeds the significance threshold of 5\% only in the case of MEDU share (see Table I). Thus the recorded estimated value is $0,8438>0,05$. Hence it follows that we cannot reject the null hypothesis, so the restriction imposed to the parameters is valid. Relating to the rest of the shares from the portfolio (see Table I), the probability of the Wald test is situated below the significance threshold of $5 \%$, for which reason we reject the null hypothesis.

Another indicator, which helps to express the correlation between the variables included in this model, is the report of determination, R-squared, as well as its derivative, Adjusted R-squared. In most cases, the values of the Adjusted R-squared coefficient are more relevant than the values of the $\mathrm{R}$-squared determination coefficient (shows the percentage in a more accurate form) and we will analyze its values, although the difference between them is not very large.

Thus, in the case of the ATB, the Adjusted R-Square is 0,2539 which means that $25,39 \%$ of the variation of the ATB portfolio return is explained on the basis of the portfolio market variation. (R-squared is 0,2622). Relative to the expansion to other representative shares on the Romanian pharmaceutical market, for the period from January 2006 to August 2013, we can state that a percentage of 33,06\% of the variation of BIO portfolio return; 7,69\% of the variation of RMAH portfolio return; $21,49 \%$ of the variation of SCD portfolio return; $-1,05 \%$ of the variation of FAMD portfolio return, $-1 \%$ of the variation of FITO portfolio return; $9,98 \%$ of the variation of MEDU portfolio return and, respectively, $-0,35 \%$ of the variation of SINT portfolio return, is explained on the basis of portfolio market variation. As you can see, there are significant differences between these values, the most receptive to the market's changes, the company listed on the Bucharest Stock Exchange, is that one whose symbol is BIO, Biofarm S.A. respectively.

\section{Testing Residue Normality - Jarque-Bera test}

The Jarque-Bera test (see Fig. 4) also plays a very important role in assessing the validity of the model and data used. It allows the simultaneous testing of the asymmetry and flattening particularities of the residuals series and examines how the empirical distribution can be approximated by a normal distribution. Thus, it can test residuals normality, assuming that the errors are normally distributed (null hypothesis).

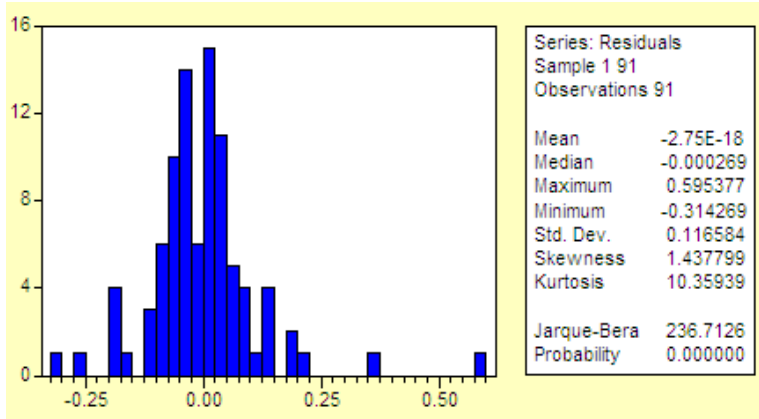

Fig. 4. Jarque-Bera Test for BIO share.

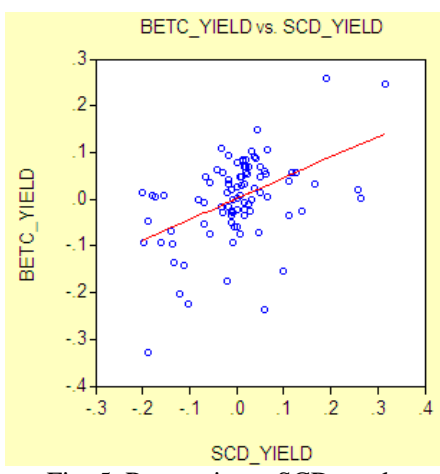

Fig. 5. Regression - SCD stock.

If it is about the BIO share, the probability associated with the Jarque-Bera test is $0.0000<0.05$, which indicates that null hypothesis is rejected. The distribution of the model cannot be approximated with a normal one (the errors are not normally distributed). As can be seen in Table I, the errors are not normally distributed in any of the eight cases. The normal distribution of the errors is important especially when making predictions on the basis of the estimated econometric equation.

The output includes the distribution histogram, the average, median, minimum and maximum values, the standard deviation, the coefficient of asymmetry, the kurtosis series and the Jarque-Bera test. Also, the errors average has a 
very low value, which means that the analysis can be substantiated on the estimated model.

Moreover, for the estimated shares portfolio, we noticed that the probability associated with the Jarque-Bera test to the significance threshold of $5 \%$ occurs for the SCD share $(0,0027)$. This is important for the values distribution to be normal. The graphical representation of regression is captured in the Fig. 5.

The portfolio of shares from the Romanian pharmaceutical industry presented in this work highlights some issues based on the different investment decisions which can be made. Thus, taking into account the excess risk brought to a well diversified portfolio, if the weight of one share increases by one percentage point (the value of $\beta$ ), then the stocks with a high value of the coefficient $\beta$ are relatively cheaper for investors.

In conclusion, the BIO stock trading, with a coefficient of 0.9257 and RMAH with a coefficient of 0.9749 respectively, are relatively cheap compared to other stocks, especially with the action FITO, whose coefficient $\beta$ is the lowest of the portfolio (0.1373). As the risk indicator beta $(\beta)$ estimated for each share is lower than zero, it can be concluded that it is about a low risk portfolio.

\section{REFERENCES}

[1] W. Sharpe., "Capital Asset Prices: A Theory of Market Equilibrium under Conditions of Risk," The Journal of Finance, vol. 19, No. 3, pp $425-442,1964$

[2] J. Treynor, Toward a Theory of the Market of Risky Assets, 1961.

[3] J. Mossin, "Equilibrium in a Capital Asset Market," Econometrica, pp. $768-783,1966$

[4] J. Lintner, "The Valuation of Risk Assets and the Selection of the Risky Investments in Stock Portfolios and Capital Budgets," The Review of Economics and Statistics, pp. 13-37, 1965.

[5] J. H. Cochrane, Asset pricing, Princeton University Press, 2001.

[6] L. A. Stout, The Mechanisms of Market Inefficiency: An Introduction to the New Finance, Cornell Law Faculty Publications, Paper 450, pp. 635-669, 2003

[7] M. Lettau and S. Ludvigson, "Test When Risk Premia are Time-Varying," Journal of Political Economy, vol. 109, no. 6, 2001.

[8] C. Alexander, "Value-At-Risk models," in Market risk analysis, Chichester, U. K.: Wiley, 2008

[9] V. Rutkauskas, V. Stasytyte, and J. Borisova, "Adequate portofolio as a conceptual model of investment profitability, risk and reliability adjustment to investor's interests," Economics and Management, vol. 14, pp. 1170-1174, 2009.

[10] A. V. Rutkauskas, A. Miečinskienè, and V. Stasytytè, "Investment decisions modeling along sustainable development concept on financial markets," Technological and Economic Development of Economy, vol. 14, no. 3, pp. 417-427, 2008.

[11] F. Serban, M. V. Stefanescu, and S. Dedu, "The efficient frontier for a portfolio that includes one risk-free asset," in ASM'11 Proc. the 5th International Conference on Applied Mathematics, Simulation, Modelling, pp. 91-95, USA: Stevens Point, 2011.

[12] M. C. Stefan. (September 30, 2012). Management decisions during crisis. Social Science Research Network. [Online]. Available: SSRN: ttp://ssrn.com/abstract=2160219 http://dx.doi.org/10.2139/ssrn.2160219

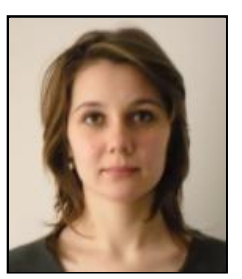

Străchinaru Adina Ionela was born in Botoşani, Romania on June 24, 1988. She graduated from the Faculty of Finance, Insurance, Banking and Stock Exchange, within the Bucharest University of Economic Studies, Romania, Finance-Banking specialization and a pedagogic course in 2010. In 2012, she graduated with a master degree in Banks and Monetary Policy, within the same higher education institution and an advanced pedagogic course. Currently, she is a Ph.D. student to Finance within the Institute of Doctoral Studies to the Bucharest University of Economic Studies, Romania.

She worked at BRD - Groupe Societe Generale, Bucharest, Romania (2010-2012) as a universal pay office operator. She has accumulated experience in quantitative analysis, confirmed in articles accepted and emerging issues: "The ipact of corporate governance measures on the performance of enterprises" (Theoretical and Applied Economics Review, Supplement International Finance and Banking Conference FI BA 2013 XIth Edition, 2013, ISSN 1844-0029, Bucharest, Romania, 2013); "Early warning systems - anticipation`s factors of banking crises" (Procedia Economics and Finance, the 7th International Conference on Applied Statistics, 15-16 November 2013, Bucharest, Romania).

Ms. Strachinaru studies Finance at Institute of Doctoral Studies of the Bucharest University of Economic Studies, Romania since October 2012 She continues her studies through publication of articles in the fields of Finance and Banking.

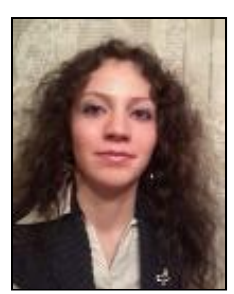

Lavinia Mihaela Guţu was born in Bucharest, Romania on September 12, 1988. She graduated the Faculty of Finance, Insurance, Banking and Stock Exchange within the Bucharest University of Economic Studies, Romania with bachelor degree in 2010. Meanwhile, she attended a pedagogic course, also completed in 2010. She continued her studies with a master degree in Banks and Monetary Policy achieved in 2012 within the same university and an advanced pedagogic course completed in the same year. In present she is a Ph.D. student within the Bucharest University of Economic Studies. She is studying Finance.

She is currently studying Finance within doctoral studies. She published some other papers - such as "The impact of corporate governance measures on the performance of enterprises" in collaboration with other authors (Theoretical and Applied Economics, Supplement International Finance and Banking Conference FI BA 2013 XIth Edition, 2013, ISSN 1844-0029, Bucharest, Romania) and "Banking Supervision In European Union" (Cross-Cultural Management Journal, Volume XV, Issue 3 - Special Issue: Collaborative Structures Vs. Competition Between Organizations Multidisciplinary Dimensions, 2013, ISSN 2286 - 0452, Bucharest, Romania). She is also working on other studies in Finance and Banking that are in process of publication.

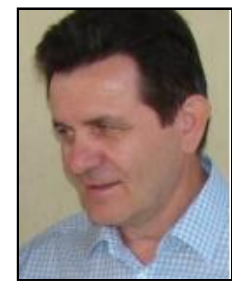

Vasile Ilie was born in Pietrari, Dâmbovița from Romania on November 26, 1952. He graduated the Faculty of Finance and Accounting within the Bucharest University of Economic Studies, Romania in 1976 and Faculty of Law - University of Bucharest Romania in 1982. Meanwhile, in 1994 he attended a Ph.D. in Economics, Finance-Banking specialization, within the Institute of Doctoral Studies, Bucharest University of Economic Studies, Romania. He continued his studies with a few training courses at: the University of Toulouse, France with four months in 1992, the University of Toulouse, France with one month in 1998, University of Geneva, Switzerland with one month in 2000, Bucharest University of Economic Studies, Romania "The education management to the distance" with postgraduate training. Currently, he is a professor at Department of Finance, Bucharest University of Economic Studies, Romania.

He worked as an accountant at the Commercial Food Enterprise in Targoviste, Romania from 1971 to 1972; economist and chief financial service at The Organisation for the maintenance and repair of equipment in Bucharest (I.I.R.U.C.) from 1976 to 1980 . He is a professor at the Bucharest University of Economic Studies, Romania, Department of Finance, as assistant professor from 1980, lecturer from 1990, associate professor in 1995 and professor in 1998, all promotions are obtained through the contest. In 1999-2008, he is the dean of Economic University College within the Bucharest University of Economic Studies, Romania and chairman of the College`s Board. Currently is a professor at Department of Finance on Mihail Moxa Street No. 5-7, code 010961, Bucharest, Sector 1, Romania. Some of his publications are: "The finances of the company", Course for distance learning, Ed. ASE, Bucharest, Romania, 144 pg., 2012, ISBN 978-606-505-568-1; "Financial management of enterprise", Ed. Meteor Press Bucharest, Romania, 424 pg., 2010, ISBN 978 973-728-457-0; "The Competitivity Of The Life Insurance Market In Romania," Theoretical and Applied Economics, General Association of Economists from Romania AGER, vol. 5(5(558), pages 172-181, July 2011, ISSN 1844-0029, etc. 